\title{
Adaptive Model for Controlling the Pollutants' Runoff to the sea Based on the Criteria of the Production Economic Efficiency and the Marine Environment Bio-diversity
}

\author{
I. E. Timchenko*, E. M. Igumnova, I. K. Ivashchenko
}

\author{
Marine Hydrophysical Institute, Russian Academy of Sciences, Sevastopol, Russian Federation \\ *e-mail: timchenko.syst.analysis@mhi-ras.ru
}

\begin{abstract}
The model of the "coast - sea" ecological-economic system, in which rational balance between the economic profits resulted from the production waste disposal and maintaining the marine environment ecological state is based on managing the system according to two criteria: the economic efficiency and the biological diversity index in the marine environment, is proposed. The balance equations of the method of adaptive balance of causes with the locally acting management agents are used for the economic and environmental subsystems "coast" and "sea”, respectively. A new method for assessing the normalized coefficients of influences calculated based on the ratios of the average values of the system variables is applied in the model equations. Influence of variations of temperature in the sea upper layer, the surface wind speed module and the chlorophyll- $a$ concentration upon the ecological-economic processes is studied based on tracing the pollution accumulation-assimilation balance in the marine environment. The results of managing the economic efficiency and the level of the marine environment bio-diversity in the mode of purifying the coastal runoff of pollution are represented. It is shown that effectiveness of managing the polluting coastal runoff is conditioned not only by penalties, but also by intensity of the pollutants' biochemical decomposition processes and by the marine environment thermodynamic characteristics.
\end{abstract}

Keywords: adaptive model, ecological-economic system, production profitability management, balance of pollution accumulation and assimilation in the sea.

DOI: 10.22449/1573-160X-2017-6-70-82

(C) 2017, I. E. Timchenko*, E. M. Igumnova, I. K. Ivashchenko

(C) 2017, Physical Oceanography

Introduction. Coastal sea zones are subjected to intensive impact of coastal runoff carrying suspended and dissolved pollutants of industrial, agricultural and domestic origin. Marine environment ability for self-purification from pollution is an important assimilation resource actively used by the coastal social-economic system. However, measures taken for cleaning up a coastal runoff from pollution are often not sufficient to preserve the marine biodiversity. Marine environment assimilative capacity has its limits because it depends on the balance of accumulation and destruction rates of the basic types of pollutants. Therefore, it is important to link the scenarios of the economic benefits from the use of marine assimilation resources with the marine environment biodiversity index dynamics to monitor the ecological state of the sea coastal zone.

For this purpose, the models of the "coast - sea" combined ecologic-economic systems are applied. Separated examples of constructing such models are available in the scientific literature on the problems of ecological economics and rational nature management [1-8]. A system approach to this problem and, particularly, the use of the Adaptive Balance of Causes principle [9-11] is prospective. Such approach was applied in [10], where an adaptive model for managing ecologicaleconomic processes of accumulation and assimilation of pollutions getting into the 
sea coastal zone from a managed coastal source was proposed. This work continues these studies using a new "coast - sea" adaptive model in which a rational balance between economic benefit from the industrial waste disposal in the sea and the preservation of marine environment ecological state is based on production management according to the following criteria: economic profitability of production, pollution level and marine environment biodiversity index.

For this purpose the model economic block was supplemented by the ecosystem one which includes chemical-biological processes forming the marine environment biodiversity index. To validate the model, there was carried out a series of simulation experiments during which the impact of the marine environment dynamics on the balance of pollutant accumulation and assimilation in the sea was investigated.

A conceptual model of ecological-economic “coast - sea” system. For managing the ecological-economic "coast - sea" system by the production profitability and marine environment biodiversity criteria, production of coastal economic subsystem goods and services should depend on sanctions imposed on it for deterioration of the marine environment condition in the coastal water area. Conceptual model of system management applied in the present study is given in Fig. 1. To assess the marine ecosystem ecological state $P L(t)$ current level of pollution concentration entering the sea with coastal runoff, $S(t)$ integral balance of pollutant accumulation and assimilation rates and $B D$ marine environment biodiversity index are used. $P L^{*}$ maximum available capacity (MAC) of pollution level, $S^{*}$ assessment of marine environment assimilative capacity and $B D^{*}$ available capacity of biodiversity index.

Marine ecosystem block includes the minimum number of processes that form $B D$ marine environment biodiversity index. A dynamic assessment based on integral balance of positive $L S_{k}$ and negative $P L$ impact factors was applied as biodiversity index:

$$
B D=C_{B D}+\sum_{k=1}^{l} b_{k} L S_{k}-a_{B D / P L} P L,
$$

where $l$ is a number of living organisms $L S_{k}$ per unit volume of marine environment most exposed to pollution getting with coastal runoff; $b_{k}$ is a relative weight of this type of organism when assessing ecological state of marine ecosystem. The food chain consisted of the lower link - PP phytoplankton concentration and the upper one $-B R$ bioresource concentration which included all other types of living organisms. Among all the ecosystem chemical elements $O X$ oxygen, $D T$ detritus and $B G$ nutrients were used. Cause-effect relationships were managed in the ecosystem by $B R$ limiting agents of bioresource for phytoplankton, nutrients and oxygen $A G_{B R}(P P, B G, O X)$ and $B G$ nutrients for oxygen and detritus $A G_{B G}(O X, D T)$.

In the economic block for managing the pollutant runoff into the sea, the following sequence of operations took place. Production volume $V$ increased with the rise in demand for the generalized product $D$ which, in its turn, resulted in the increase of pollutant volume getting into the sea. This leaded to the rise of pollutant 
volume in the marine environment $P L$ and, as a result, $A G_{T X}\left(P L, P L^{*}\right)$ management agent imposed the sanctions $T X$ which increased the production cost $E$. The management of output product volumes was carried out by $A G_{V}(P, E)$ agent that continuously compared product cost with product market price $P$. When product cost became higher than the cost: $E>P$ and a condition of production profitability $E F$ was violated this agent reduced (or stopped) the product output. Additional penalty increase took place for exceeding $P L^{*}$ pollution MAC. After production reduction or stop, pollutant inflow to the sea decreased and the processes of marine environment self-purification leaded to the decrease in pollutant concentration in the sea. Therefore, the reverse sequence of events occurred: a size of sanctions and production cost value decreased. As a result of $E<P$ condition onset, $A G_{V}(P, E)$ management agent restored the production output up to the level of a demand for it.

Current balance of pollution accumulation and assimilation rates was controlled by $A G_{T X}\left(S, S^{*}\right)$ management agent. It increased $T X$ sanctions for pollution when $S(t)$ balance of volumes of accumulated and assimilated pollutions exceeded $S^{*}$ value determined by the marine ecosystem assimilative properties. In addition, when marine environment biodiversity index dropped below $B D^{*}$ predetermined threshold value, $A G_{B D}\left(B D, B D^{*}\right)$ management agent also began to reduce the product output.

In the management model a regime for coastal runoff purification from pollutions hazardous for the ecosystem was provided. For this aim, a fund of new technologies $T X_{\text {acc }}$ formed of the penalties for pollution $T X_{\text {acc }}$ was included into the structure of the model (Fig. 1). When the volume of this fund increased up to $T X_{\text {acc }}^{*}$ value, $A G_{P L}\left(T X_{a c c}, T X_{a c c}^{*}\right)$ management agent simulated an inclusion of coastal runoff purification mode and, as a consequence, a drop of pollution concentration in the marine environment $P L$ took place.

Integral balance of pollutant accumulation and assimilation was difference $S(t)$ of two components:

$$
S(t)=S_{a c c}(t)-S_{a s s}(t)=a_{P L / V} \int_{0}^{t}[1-R(\tau)] V(\tau) d \tau,
$$

where $S_{\text {acc }}(t)$ is a volume of accumulated pollutions; $S_{\text {ass }}(t)$ is their assimilated volume; $R(t)$ is pollution assimilation relative rate - a function of assimilative capacity that was a relationship of assimilated pollution volume to their total accumulated one $R(t)=S_{\text {ass }} / S_{\text {acc }}$. Due to finite value of marine environment assimilative capacity, for this ecosystem there was a maximum permitted value (threshold value) of pollution accumulation and assimilation balance function (2) which we denote as $S^{*}$. Within the assimilative capacity, at $S \leq S^{*}, R(t)$ function took the constant $R_{\max }$ values from $(0 \leq R(t) \leq 1)$ range. $S^{*}$ value depended on the intensity of pollutant biochemical destruction, TW sea temperature as well as the transport and turbulent diffusion of water masses. 


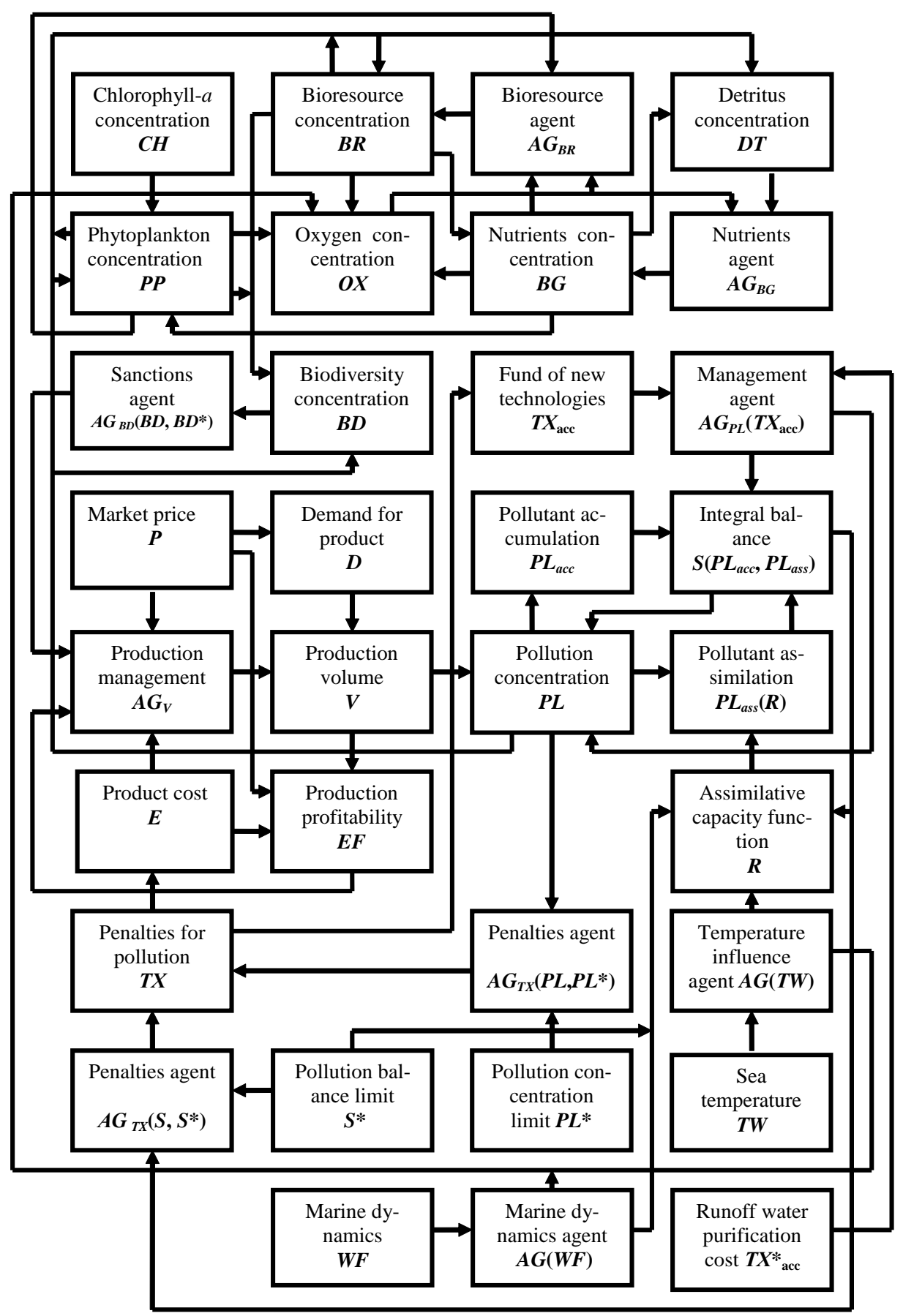

Fig. 1. Conceptual model of the "coast - sea" ecological-economic model management by production profitability and marine environment biodiversity criteria 
For $R(t)$ function the following management model was applied:

$$
\begin{gathered}
R(t)=I F\left\{R(t)>1 ; 1 ; I F\left[S<S^{*} ; R_{\max } ; R_{\max } \exp \left(-\alpha_{R} \tau\right)\right]+A G[T W(t)]+A G[W F(t)]\right\},(3) \\
A G[T W(t)]=a_{R / T W} I F\left\{T W(t)>0 ; 1-\exp \left[-b_{R / T W} T W(t)\right] ; 0\right\} \\
A G[W F(t)]=a_{R / W F} I F\left\{W F(t)>0 ; 1-\exp \left[-b_{R / W F} W F(t)\right] ; 0\right\}
\end{gathered}
$$

Dynamic equations of economic block of ecological-economic system adaptive model. The equations were constructed using the modular ones of the Adaptive Balance of Causes method ( $A B C$-method) [10] and a scheme of causeeffect relations of the simulated processes (Fig. 1). It was considered that a variety of interrelated processes represented by $\left\{u_{i}\right\}$ functions which take the values from $0 \leq u_{i} \leq 2 C_{i}$ segments, where $C_{i}$ is mean values of the processes, was applied to construct the management system model. $u_{i}$ processes formed the material balances of modeled substances according to the cause-effect relations and were represented by the following relationships

$$
u_{i}=C_{i}+\sum_{j=1, i \neq j}^{n} a_{i j} u_{j}+A_{i},
$$

where $a_{i j}$ are the coefficients if intrasystem effects; $n$ is a number of processes; $A_{i}$ is external effects applied to the ecosystem. In [10-14] it is shown that the system of equations of the $A B C$-method is constructed to retain the dynamic balances of the modeled substance masses (4). The following general system of equations corresponds to this aim:

$$
\frac{d u_{i}}{d t}=2 r_{i} u_{i}\left[C_{i}-\left(u_{i}-\sum_{j=1, i \neq j}^{n} a_{i j} u_{j}-A_{i}\right)\right](i, j=1,2, \ldots, n),
$$

where $r_{i}$ are specific rates of variable variation.

Material balances (4) of intrasystem and external effects in the equations (5) are preserved as increments in the number of reaction products relative to their $C_{i}$ mean values on the condition that intrasystem and external effects do not output variables outside the areas of their determination $\left(0 \leq u_{i} \leq 2 C_{i}\right)$ :

$$
u_{i}=\operatorname{IF}\left[u_{i}<0 ; 0 ; \operatorname{IF}\left(u_{i}>2 C_{i} ; 2 C_{i} ; u_{i}\right)\right] .
$$

The methods for assessing $a_{i j}$ coefficients of effects considered in [10-14] are based on this assumption.

Using the $A B C$-method equations (5) and notations of cause-effect relations in the system conceptual model (Fig. 1) we write out the equations of coastal economic subsystem.

An equation of demand for production:

$$
\frac{d D}{d t}=2 r_{D} D\left[C_{D}-\left(D_{i}+a_{D / P} P-D^{*}\right)\right]
$$




$$
D=I F\left[D<0 ; 0 ; \operatorname{IF}\left(D>2 C_{D} ; 2 C_{D} ; D\right)\right],
$$

where $D^{*}$ function of external effect determines the demand dynamics and $C_{D}$ constant sets its mean value.

An equation for production volume of goods and services:

$$
\begin{gathered}
\frac{d V}{d t}=2 r_{V} V\left\{C_{V}-\left[V+A G_{V}(P, E)+A G_{B D}\left(B D, B D^{*}\right)-a_{V / D} D\right]\right\}, \\
V=I F\left[V<0 ; 0 ; I F\left(V>2 C_{V} ; 2 C_{V} ; V\right)\right], \\
A G_{V}(P, E)=I F\left\{P>E ; 0 ; V_{E}^{*}\left[1-\exp \left(-b_{V} \tau\right)\right]\right\}, \\
A G_{B D}\left(B D, B D^{*}\right)=I F\left\{B D>B D^{*} ; 0 ; V_{B D}^{*}\left[1-\exp \left(-b_{B D} \tau\right)\right]\right\} .
\end{gathered}
$$

An equation for pollution concentration:

$$
\begin{gathered}
\frac{d P L}{d t}=2 r_{P L} P L\left\{C_{P L}-\left[P L-a_{P L / V} I F\left\{S(t)<S^{*} ; V(t) ; V(t)+\int_{0}^{t}[1-R(\tau)] V(\tau) d \tau\right\}+\right.\right. \\
\left.\left.+A G_{P L / T X_{a c c}}\left(T X_{a c c}, T X_{a c c}^{*}\right)\right]\right\} \\
P L=I F\left[P L<0 ; 0 ; I F\left(P L>2 C_{P L} ; 2 C_{P L} ; P L\right)\right], \\
A G_{P L / T X_{a c c}}\left(T X_{a c c}, T X_{a c c}^{*}\right)=I F\left\{T X_{a c c}<T X_{a c c}^{*} ; 0 ; P L\left[1-\exp \left(-b_{P L_{T X}} \tau\right)\right]\right\}, \\
T X_{a c c}(t)=\int_{0}^{t} T X(\tau) d \tau .
\end{gathered}
$$

An equation for penalties for marine environment pollution:

$$
\begin{gathered}
\frac{d T X}{d t}=2 r_{T X} T X\left\{C_{T X}-\left[T X-a_{T X / P L} P L-A G_{T X / P L^{*}}\left(P L, P L^{*}\right)-A G_{T X / S^{*}}\left(S, S^{*}\right)+T X^{*}\right]\right\},(11) \\
T X=I F\left[T X<0 ; 0 ; I F\left(T X>2 C_{T X} ; 2 C_{T X} ; T X\right)\right], \\
A G_{T X / P L^{*}}\left(P L, P L^{*}\right)=I F\left\{P L<P L^{*} ; 0 ; a_{T X / P L^{*}}\left(P L-P L^{*}\right)\left[1-\exp \left(-b_{T X / P L^{*}} \tau\right)\right]\right\}, \\
A G_{T X / S^{*}}\left(S, S^{*}\right)=I F\left\{S<S^{*} ; 0 ; a_{T X / S-S^{*}}\left(S-S^{*}\right)\left[1-\exp \left(-b_{T X / S-S^{*}} \tau\right)\right]\right\},
\end{gathered}
$$

where $T X^{*}$ is a constant managing the total volume of sanctions.

An equation for the coastal subsystem production cost:

$$
\begin{aligned}
& \frac{d E}{d t}=2 r_{E} E\left[C_{E}-\left(E-a_{E / T X} T X+E^{*}\right)\right], \\
& E=I F\left[E<0 ; 0 ; I F\left(E>2 C_{E} ; 2 C_{E} ; E\right)\right] .
\end{aligned}
$$

An assessment of production economic profitability was carried out using a logarithm of ratio of $I_{\text {acc }}(t)$ economic system income to $E_{\text {acc }}(t)$ expenditures accumulated over $(0, t)$ time period:

$$
I_{\text {acc }}=\int_{0}^{t} P^{*} V(t) d t, \quad E_{\text {acc }}=\int_{0}^{t} E(t) V(t) d t, \quad E F=\ln \frac{1+I_{\text {acc }}}{1+E_{\text {acc }}} .
$$


Dynamic equations of ecologic block of the ecological-economic system adaptive model. Modular equations of the Adaptive Balance of Causes method (5) allowed one to construct the following system of equations of the "sea" subsystem adaptive model.

An equation for biodiversity index:

$$
\begin{gathered}
\frac{d B D}{d t}=2 r_{B D} B D\left[C_{B D}-\left(B D-a_{B D / P P} P P-a_{B D / B R} B R+a_{B D / P L} P L\right)\right], \\
B D=I F\left[B D<0 ; 0 ; \operatorname{IF}\left(B D>2 C_{B D} ; 2 C_{B D} ; B D\right)\right] .
\end{gathered}
$$

An equation for phytoplankton concentration:

$$
\begin{gathered}
\frac{d P P}{d t}=2 r_{P P} P P\left\{C_{P P}-\left[P P+a_{P P / B R} B R-a_{P P / B G} B G+a_{P P / P L} P L-a_{P P / C H} C H\right]\right\}, \\
P P=I F\left[P P<0 ; 0 ; I F\left(P P>2 C_{P P} ; 2 C_{P P} ; P P\right)\right] .
\end{gathered}
$$

An equation for bioresource concentration:

$$
\begin{gathered}
\qquad \frac{d B R}{d t}=2 r_{B R} B R\left\{C_{B R}-\left[B R-A G_{B R}(O X, P P, B G)+a_{B R / P L} P L\right]\right\} \\
B R=I F\left[B R<0 ; 0 ; I F\left(B R>2 C_{B R} ; 2 C_{B R} ; B R\right)\right], \\
A G_{B R}(O X, P P, B G)=I F\left[M_{B R}(t)=a_{B R / O X} O X(t) ; a_{B R / O X} O X(t) ; 0\right]+ \\
+I F\left[M_{B R}(t)=a_{B R / P P} P P(t) ; a_{B R / P P} P P(t) ; 0\right]+I F\left[M_{B R}(t)=a_{B R / B G} B G(t) ; a_{B R / B G} B G(t) ; 0\right], \\
\text { where } M_{B R}(t)=\arg \min \left[a_{B R / B G} O X(t) ; a_{B R / P P} P P(t) ; a_{B R / B G} B G(t)\right] .
\end{gathered}
$$

An equation for oxygen concentration:

$$
\begin{aligned}
& \frac{d O X}{d t}=2 r_{O X} O X\left\{C_{O X}-\left[O X+a_{O X / B R} B R+a_{O X / B G} B G-a_{O X / P P} P P+\right.\right. \\
& +A G[T W(t)]-A G[W F(t)]\} \\
& \quad O X=I F\left[O X<0 ; 0 ; \operatorname{IF}\left(O X>2 C_{O X} ; 2 C_{O X} ; O X\right)\right] .
\end{aligned}
$$

An equation for the concentration of nutrients:

$$
\begin{aligned}
& \frac{d B G}{d t}=2 r_{B G} B G\left\{C_{B G}-\left[B G-A G_{B G}(O X, D T)+a_{B G / P P} P P+a_{B G / B R} B R\right]\right\}, \\
& B G=I F\left[B G<0 ; 0 ; I F\left(B G>2 C_{B G} ; 2 C_{B G} ; B G\right)\right], \\
& A G_{B G}(O X, D T)=I F\left[M_{B R}(t)=I F\left[M_{B G}(t)=a_{B G / O X} O X(t) ; a_{B G / O X} O X(t) ; 0\right]+\right. \\
& +I F\left[M_{B G}(t)=a_{B G / D T} D T(t) ; a_{B G / D T} D T(t) ; 0\right]
\end{aligned}
$$

where $M_{B G}(t)=\arg \min \left[a_{B R / O X} O X(t) ; a_{B R / D T} D T(t)\right]$.

An equation for detritus concentration:

$$
\begin{gathered}
\frac{d D T}{d t}=2 r_{D T} D T\left\{C_{D T}-\left[D T-a_{D T / B R} B R-a_{D T / P P} P P+a_{D T / O X} O X-a_{D T / P L} P L\right]\right\}, \\
D T=I F\left[D T<0 ; 0 ; I F\left(D T>2 C_{D T} ; 2 C_{D T} ; D T\right)\right] .
\end{gathered}
$$


Numerical experiments with the model. Numerical experiments were carried out with the constructed model. Dimensional variables of $u_{i}^{\prime}$ model and $A_{i}^{\prime}$ external effects which have $C_{u_{i}^{\prime}}$ and $\overline{A_{i}^{\prime}}$ mean values were represented in dimensionless form $u_{i}$ and $A_{i}$ using a transformation:

$$
C_{u} u_{i}^{\prime}=C_{u_{i}^{\prime}} u_{i}, \bar{A} A_{i}^{\prime}=\bar{A}_{i}^{\prime} A_{i} .
$$

According to relations (20), it is enough to multiply $u_{i}$ results of the calculations by $C_{u_{i}^{\prime}} C_{u}^{-1}$ to return to the initial size values of variables. The calculations were carried out for 370 steps of dimensionless time with $\Delta t=0.1$ step of computations. When performing simulation experiments, mean values of variables were set from $(0,10)$ variation range, the coefficients of effects had the values from $(0,1 ; 0,5)$ interval.

In the first series of experiments model manageability and its sensitivity to the changes in parameters determining the impact of penalties on the pollution level and production profitability were investigated. Initially, $T W(t)$ and $W F(t)$ thermodynamic factors were not taken into account in order to assess subsequently their impact on the balance of pollution accumulation and assimilation. Process scenarios for an unfavorable case for an ecosystem, when pollution assimilation rate is low $\left(R_{\max }=0,05\right)$ and penalties for pollution are absent $(T X=0)$, were constructed. These scenarios are given in Fig. 2, $a-d$.
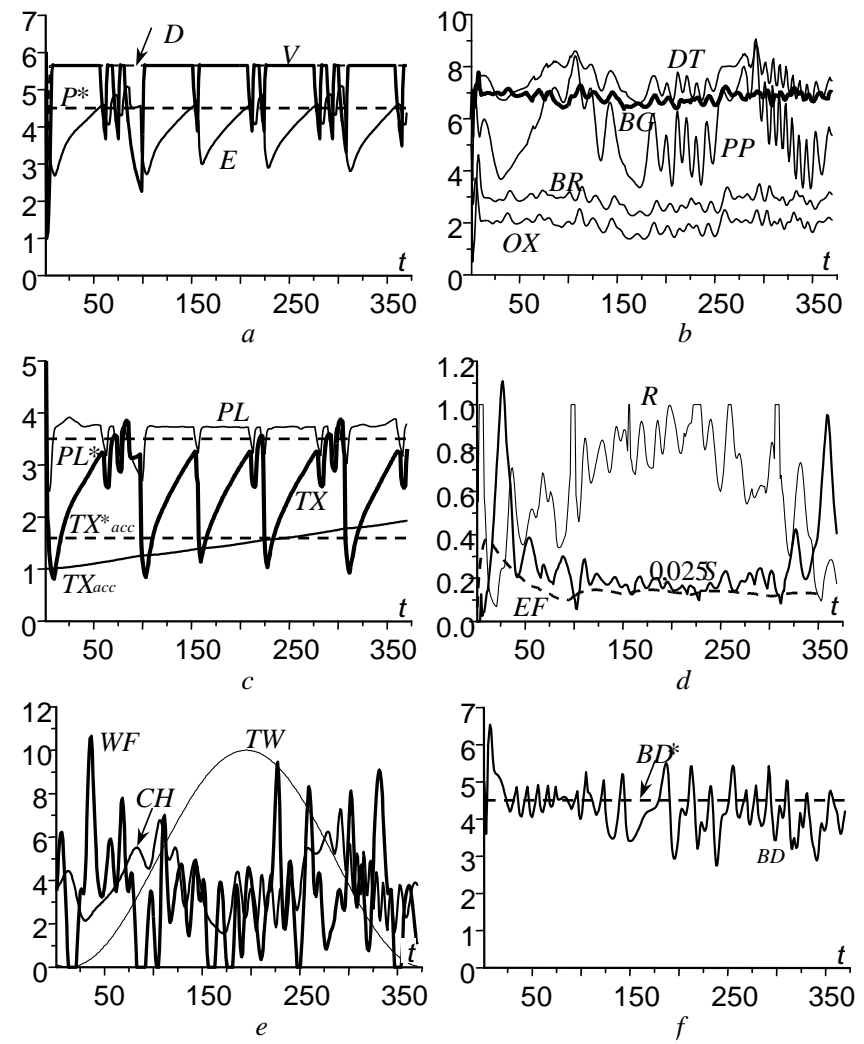

Fig. 2. Scenarios of ecological-economic processes with no regard to the impact of marine environment dynamics: $a, b, c, d$ - an increase of a sea pollution level when production output is not limited; $e, f, g, h-V$ production output volume management by $P L$ pollution level and $S$ balance of pollution accumulation and assimilation rates. See the explanation of symbols in Fig. 1

PHYSICAL OCEANOGRAPHY ISS. 6 (2017) 
In the absence of sanctions for pollution, the economic system produced products at $V=D$ level of constant demand for it as $P>E$ condition of production profitability was satisfied (Fig. 2, a), and there was no output management. Due to low assimilation rate $P L$ marine environment pollution level sharply increased (Fig. 2, c) and this affected the scenarios of processes in the marine ecosystem (Fig. 2, b). An index of its biodiversity decreased due to the drop of $P P$ phytoplankton and $B R$ bioresource concentrations and $P L$ pollution level dramatically increased. Production profitability remained stably high at that (Fig. 2, d).

After running a production output management, scenarios of ecologicaleconomic processes have undergone significant changes. In the initial time period along with $P L$ sea pollution level increase $P L^{*}$ MAC predetermined value was exceeded. This leaded to a dramatic increase of $T X$ sanctions (Fig. 2, $g$ ) and violation of $P>E$ production profitability condition (Fig. 2, $e$ ). This resulted in a sequence of short-time and more prolonged production output limitations represented in Fig. 2, e. During the periods of output limitation $P L$ pollution concentration (Fig. 2, g) and $S$ total balance of accumulated pollutions (Fig. 2, h) decreased. This gradually created conditions for production volume resumption on $V=D$ level of demand.

Marine ecosystem reaction to the marine environment pollution level management is given in Fig. 2, $f$. From the comparison of these processes with the scenarios in Fig. 2, $b$ it follows that coastal runoff management allow one to control variation of ecosystem variable concentration and affect its biodiversity index. The results of the next series of experiments are shown in Fig. 3.

The reaction of "coast - sea" ecological-economic model to external effects was assessed: observations of chlorophyll $a$ concentration, sea temperature and near-water wind velocity modulus. Simulated scenarios for the intra-annual variability of these processes are shown in Fig. 3, e. The coefficients and parameters of the model were retained the same. The regimes of runoff water purification and system management by biodiversity index were not used in this experiment.

External effects significantly changed the ecosystem assimilative properties. Assimilation rate significantly increased and the balance of pollution accumulation and assimilation noticeably dropped (Fig. 3, d). As a result, $P L$ concentration of pollutions began to decrease significantly faster than in the previous experiment (Fig. 2, g) and it was "bounded" to MAC $P L^{*}=3.5$ value. Production output was mainly at the level of demand, although it was accompanied by short-term reductions in the production output volumes (Fig. 3, a). Production profitability (Fig. 3, $d$ ) increased approximately twofold in comparison with the one shown in Fig. $2, h$.

The scenarios of ecological processes shown in Fig. 3, $b$ demonstrate high variability of $P P$ phytoplankton and $D T$ detritus concentrations. $O X$ oxygen concentration turned out to be less variable (it was used in calculations $\left(a_{O X / P P}=0.3\right)$ ) due to a small coefficient of effect on it from the phytoplankton. The scenarios of $B R$ bioresource and $B G$ nutrients had the mentioned variability character as resource limiting agents took into account the minimum values of oxygen concentrations (Fig. 3, $b$ ) in the equations for these variables. 

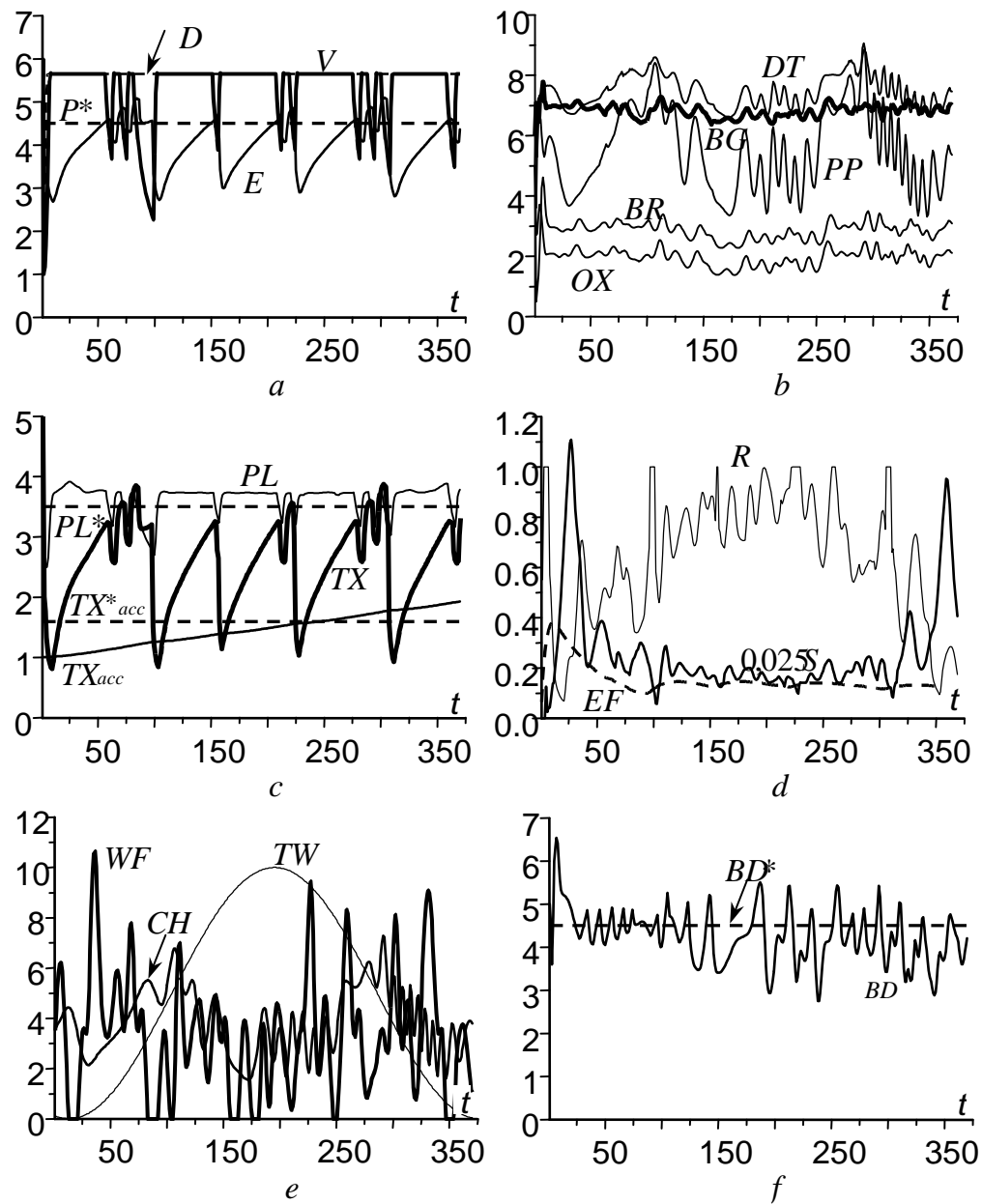

Fig. 3. Variability of processes in the "coast - sea" ecological-economic system under effect of TW temperature, WF near-water wind and $\mathrm{CH}$ chlorophyll-a concentration simulated scenarios. The regimes of runoff water purification from the pollutions and system management by biodiversity index were not applied. The legend is given in Fig. 1

The scenario of marine environment biodiversity index calculated by the equation (14) is given in Fig. 3, $f$. Its values fell below $B D^{*}=4.5$ maximum available value, which was determined in this experiment. The system management by this criterion was not provided but this scenario was constructed for comparison with the results of subsequent experiments.

During the further experiments all available system management capabilities were used simultaneously. In the equation for production output (8) $A G_{B D}\left(B D, B D^{*}\right)$ management agent, which reduced the production output when marine environment biodiversity index fell below a predetermined maximum available value $B D^{*}=4.5$, was activated. In the equation for marine environment pollution level (9) $A G_{P L / T X_{a c c}}\left(T X_{a c c}, T X_{a c c}^{*}\right.$ ) management agent (which simulated the coastal runoff purification when the assets from penalties for pollution accumulatPHYSICAL OCEANOGRAPHY ISS. 6 (2017) 
ing in $T X_{a c c}$ fund of new technologies reached $T X_{\text {acc }}^{*}$ value) was activated. The results of managing the level of marine environment pollution by coastal runoff in coastal runoff purification regime and the one of control over marine environment biodiversity index are given in Fig. 4.
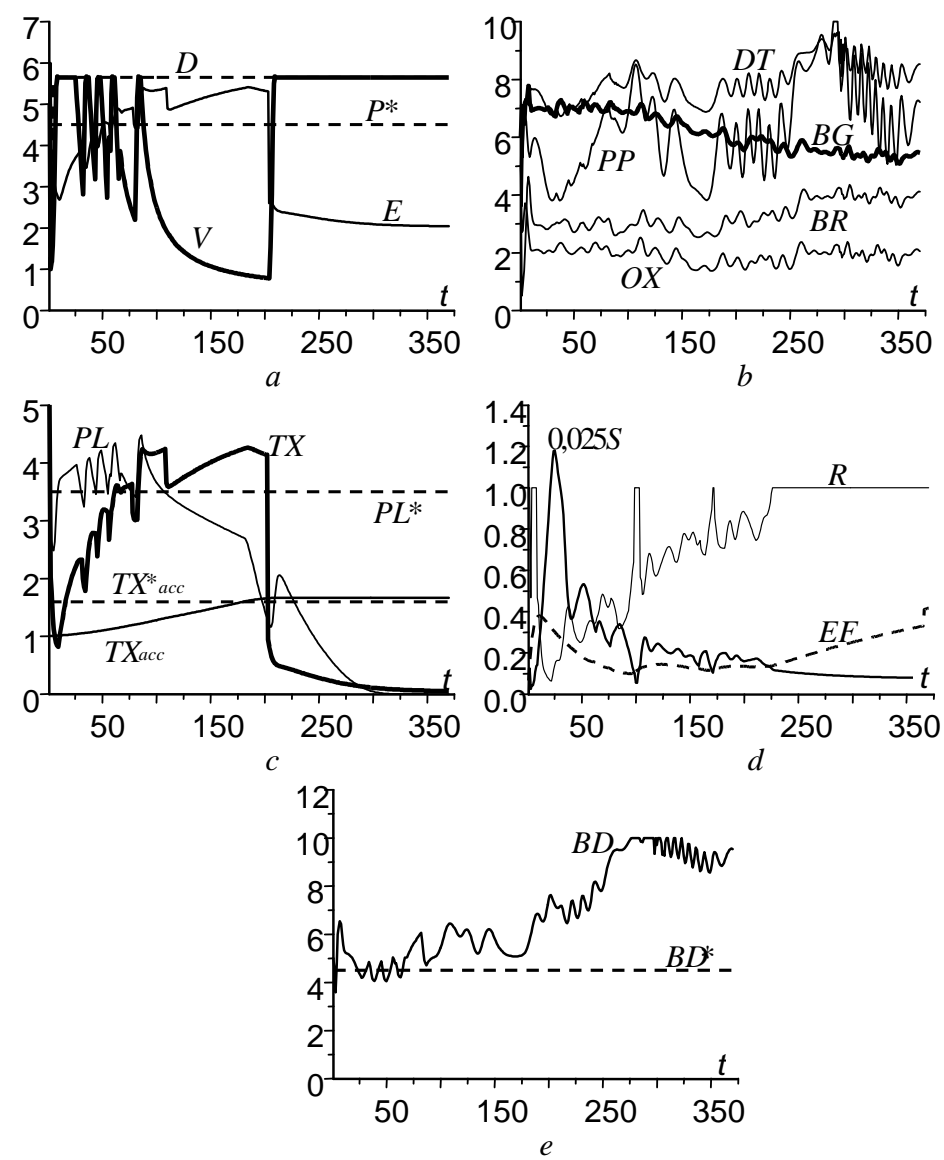

Fig. 4. Scenarios of ecological-economic processes with regard to control over marine environment biodiversity index at coastal runoff purification regime activated on $175^{\text {th }}$ step of calculations. The legend is given in Fig. 1

Activation of agent for system management by biodiversity index resulted in short-term limitations of $V$ production volumes (Fig. 4, a) already at the initial time period of the experiment, before the $70^{\text {th }}$ computational step, as $B D$ index fell below $B D^{*}$ value (Fig. $4, e$ ). At the same time, $T X$ penalties for pollution sharply increased (Fig. 4, c). Due to this, $E$ production cost exceeded $P^{*}$ output cost (Fig. 4, a) and production volume was limited from the $70^{\text {th }}$ to $205^{\text {th }}$ steps of computation. In this time period $P L$ pollution concentration decreased but the penalties for pollution remained and even increased (Fig. 4, $c$ ) as $S$ balance of accumulated and assimilated pollutions still exceeded the predetermined $S^{*}=0,05$ value. The rate of $P L$ concentration drop sharply increased at $175^{\text {th }}$ step when the value of $T X_{\text {acc }}^{*}$ fund of new technologies reached $T X_{\text {acc }}^{*}$ value (Fig. 4, $c$ ). 
After activating the regime for coastal runoff purification, relative rate of pollution assimilation increased up to $R_{\max }=1$ maximum value (Fig. $4, d$ ). $P L$ pollution concentration dropped down to zero (Fig. 4, $c$ ) and $E F$ production profitability acquired a trend of steady growth (Fig. 4, $d$ ). An improvement of runoff water quality significantly increased $B D$ marine environment biodiversity index. The obtained scenario of $B D$ index (Fig. 4, e) is favorably different from the previous one (Fig. 3, $f$ ) when the fund of new technologies was not used. The decrease of index in the end of the experiment is explained by a phytoplankton concentration drop (Fig. $4, b$ ) caused by predetermined annual course of the sea temperature (Fig. 3, $e$ ).

Conclusion. The management of complex system which includes coastal social-industrial complex and an ecosystem of the coastal marine environment is aimed at obtaining economic benefits from the disposal of industrial and domestic wastes through the sea assimilative resources with the necessary observance of conditions that prevent irreversible degradation of the marine ecosystem [12-15]. In the present work the mechanism for satisfying these conditions by imposing penalties (on the production) which decrease its profitability and limit the pollutant inflow into the sea.

The results of computational experiments with "coast - sea” adaptive model showed that it can be used to forecast integral values of pollution level and coastal ecosystem biodiversity index along with the forecast of scenarios of generalized coastal subsystem production processes (production volumes, its cost, profitability, etc.). Due to the inclusion of management agents into the model, it became possible to determine the most profitable regimes of marine environment assimilative capacity use by varying the size of penalties for pollution. Consideration of sea temperature and the upper layer wind mixing significantly increase assimilative capacity of marine environment.

An adaptive approach to the joint description of marine ecological and coastal economic processes is necessary for creating information technologies for environmental management in the sea coastal zone. Management of "coastal runoff coastal marine environment" complex system implies the specification of sources and chemical composition of pollution, as well as the use of a dynamic model for the distribution and transformation of pollution in the sea.

Acknowledgements. The research was carried out within the framework of the State Order No. 0827-2014-0010 "Complex interdisciplinary research of oceanographic processes determining the functioning and evolution of the Black Sea and the Azov Sea ecosystems on the basis of modern methods for marine environment monitoring and grid technologies"(“Fundamental oceanography” code).

REFERENCES

1. Daly, H. and Farley, J., 2010. Ecological Economics: Principles and Applications. Washington: Island Press, $544 \mathrm{p}$.

2. Voinov, A., 2008. Systems Science and Modeling for Ecological Economics. New York: Academic Press, $430 \mathrm{p}$. 
3. Izrael', Yu.A., Tsyban', A.V., Venttsel', M.V. and Shigaev, V.V., 1988. Nauchnoe Obosnovanie Ekologicheskogo Normirovaniya Antropogennogo Vozdeystviya na Morskuyu Ekosistemu (Na Primere Baltiyskogo Morya) [Scientific Basis for Ecological Regulation of Anthropogenic Impact on the Marine Ecosystem (on the Example of the Baltic Sea)]. Okeonologiya, 28(2), pp. 34-42 (in Russian).

4. Ofiara, D.D. and Seneca, J.J., 2001. Economic Losses from Marine Pollution: a Handbook for Assessment. Washington: Island Press, 320 p. Available at: https://ageconsearch.umn.edu/bitstream/34963/1/sp07wi01.pdf [Accessed: 16 April 2017].

5. Costanza, R., Voinov, A., Boumans, R., Maxwell, T., Villa, F., Wainger, L. and Voinov, H., 2002. Integrated Ecological Economic Modeling of the Patuxent River Watershed. Maryland. Ecological Monographs, 72(2), pp. 203-231. Available at: https://pdfs.semanticscholar.org/97f3/855f11e1b63dd219e989b0987838ebed99ca.pdf [Accessed: 14 April 2017].

6. Shogren, J.F., Parkhurst, G.M. and Settle, C., 2003. Integrating Economics and Ecology to Protect Nature on Private Lands: Models, Methods and Mindsets. Environ. Sci. Policy, [e-journal] 6(3), pp. 233-242. doi:10.1016/S1462-9011(03)00041-8

7. Crépin, A.-S., Norberg, J. and Mäler, K.-G., 2011. Coupled Economic-Ecological Systems with Slow and Fast Dynamics. - Modelling and Analysis Method. Ecol. Econ., [e-journal] 70(8), pp. 1448-1458. doi:10.1016/j.ecolecon.2011.02.004

8. $\quad$ Samhouri, J.F. and Levin, P.S., 2012. Linking Land- and Sea-Based Activities to Risk in Coastal Ecosystems. Biol. Conserv., [e-journal] 145(1), pp. 118-129. doi:10.1016/j.biocon.2011.10.021

9. Timchenko, I.E., Igumnova, E.M. and Timchenko, I.I., 2000. Sistemnyy Menedzhment i ABCTekhnologii Ustoychivogo Razvitiya [System Management and ABC-technologies of Sustainable Development]. Sevastopol: MHI NAN Ukrainy, 225 p. (in Russian).

10. Timchenko, I.E., Ivashchenko, I. K. and Igumnova, E.M., 2017. Management of EcologicalEconomic Processes of Pollution Accumulation and Assimilation in the Coastal Zone Marine Environment. Physical Oceanography, [e-journal] (1), pp. 68-83. doi:10.22449/1573-160X2017-1-68-83

11. Timchenko, I.E., Igumnova, E.M. and Timchenko, I.I., 2016. Adaptive Balance Models for Environmental-Economic Systems. CreateSpace Indep. Publ. Platf., 486 p.

12. Halpern, B.S., Walbridge, S., Selkoe, K.A., Kappel, C.V., Micheli, F., D'Agrosa, C., Bruno, J.F., Casey, K.S. and Ebert, C., 2008. A Global Map of Human Impact on Marine Ecosystems. Science, [e-journal] 319(5865), pp. 948-952. doi:10.1126/science.1149345

13. Elofsson, K., Folmer, H. and Gren, I.-M., 2003. Management of Eutrophicated Coastal Ecosystems: A Synopsis of the Literature with Emphasis on Theory and Methodology. Ecol. Econ., [e-journal] 47(1), pp. 1-11. doi:10.1016/j.ecolecon.2003.09.001

14. McCay, B.J. and Jones, P.J.S., 2011. Marine Protected Areas and the Governance of Marine Ecosystems and Fisheries. Conserv. Biol., [e-journal] 25(6), pp. 1130-1133. doi:10.1111/j.1523-1739.2011.01771.x

15. Börger, T., Beaumont, N.J., Pendleton, L., Boyle, K.J., Cooper, P., Fletcher, S., Haab, T., Hanemann, M. and Hooper, T.L. [et al], 2014. Incorporating Ecosystem Services in Marine Planning: The Role of Valuation. Mar. Policy, [e-journal] 46, pp. 161-170. doi:10.1016/j.marpol.2014.01.019 